\title{
Artificial Intelligence and Cognitive Computing: Methods, Technologies, Systems, Applications and Policy Making
}

\author{
Miltiadis D. Lytras ${ }^{1,2}$ (D) and Anna Visvizi ${ }^{3,4, *(D)}$ \\ 1 Effat College of Engineering, Effat University, Jeddah P.O. Box 34689, Saudi Arabia; mlytras@acg.edu \\ 2 King Abdulaziz University, Jeddah 21589, Saudi Arabia \\ 3 Effat College of Business, Effat University, Jeddah P.O. Box 34689, Saudi Arabia \\ 4 SGH Warsaw School of Economics, Al. Niepodległości 162, 02-554 Warsaw, Poland \\ * Correspondence: avisvizi@gmail.com
}

check for updates

Citation: Lytras, M.D.; Visvizi, A. Artificial Intelligence and Cognitive Computing: Methods, Technologies, Systems, Applications and Policy Making. Sustainability 2021, 13, 3598. https://doi.org/10.3390/su13073598

Received: 18 March 2021

Accepted: 20 March 2021

Published: 24 March 2021

Publisher's Note: MDPI stays neutral with regard to jurisdictional claims in published maps and institutional affiliations.

Copyright: (c) 2021 by the authors. Licensee MDPI, Basel, Switzerland. This article is an open access article distributed under the terms and conditions of the Creative Commons Attribution (CC BY) license (https:// creativecommons.org/licenses/by/ $4.0 /)$.
Artificial intelligence (AI) and cognitive computing (CC) are subject of increased attention of both academia and industry today [1] The understanding is that AI- and CCenhanced methods and techniques create a variety of opportunities relating to improving basic and advanced business functions, including production processes, logistics, financial management and others. AI-enhanced tools and methods tend to offer more precise results in the field of engineering, financial accounting, tourism, air-pollution management and many more. The objective of this special issue was to bring together diverse communities of scholars and engage in a broad discussion on the role of AI and CC in today's society, including the process of policy-making. A great number of submissions was received in response to the initial call for papers. Out of these, 14 papers were eventually selected for inclusion in this volume. These papers have been organized in three thematic groups: focusing on the use of AI-enhanced tools in the broadly understood field of engineering; exploring the value of AI- and CC-based techniques in the assembly line, internet of things (IoT), etc.; and querying the uses of AI-enhanced methods in the fields of tourism, safety and security, and policy-making.

In their paper titled "Application of Machine Learning in Evaluation of the Static Young's Modulus for Sandstone Formations" [2] the authors showcase how machine learning can be useful in predicting the mechanical characteristics of reservoir formations, especially of sandstone formations. This includes the evaluation of the wellbore stability. Remaining in the field of engineering, the following paper [3] applies advanced AI-based methods to study and enhance the productivity of wells. By focusing on the case of fishbone multilateral wells, the authors develop and apply several AI methods to estimate the performance of fishbone wells. In a similar context, the authors of the next paper [4] examine the problem of carbon dioxide $\left(\mathrm{CO}_{2}\right)$ injections as a method for improving hydrocarbon recovery. As the authors explain, the minimum miscibility pressure (MMP) has a great effect on the performance of $\mathrm{CO}_{2}$ flooding. While several methods exist to determine the MMP, they are costly and time-consuming, and may still produce estimation errors. AI-enhanced methods to determine the MMP are highlighted as more efficient in this context. In the same vein, the following paper [5] elaborates on the value added of AI-enhanced methods in estimating total organic carbon (TOC) content in unconventional shale resources evaluation. Always in the same context, the next paper [6] included in this volume discusses in which ways hybrid AI models can effectively predict the elastic behavior of sandstone rocks. The author of the following paper [7] provides insights into the use of AI in predicting the rheological properties of water-based drill-in fluid. AI-enhanced methods and application in the domain of air quality analysis, visualization and response generation are discussed in the paper that follows [8]. To this end, the authors develop an interactive visual analytic system for recognizing, exploring and summarizing regular patterns, as well as detecting, classifying and interpreting abnormal cases.

Papers included in the second part of the volume address different aspects of AI application. For instance, Chang et al. [9] apply advanced AI-enhanced methods to establish 
an accurate decision-making method between the quality level of the diesel engine and the parameters of assembly clearance. Han et al. [10] focus on the challenge of energy conservation in context of the internet of things (IoT). The authors stress, on the one hand, the salience of wireless nodes in enabling communication among devices, and on the other hand, the caveats pertaining to recharging the batteries of these wireless nodes. To navigate the problem, the authors propose a novel hybrid unequal multi-hop clustering based on density (HCD) designed to increase the network lifetime. The value of AI-based methods is further evidenced in the following paper [11] that proposes a correction methodology for Long Short-Term Memory (LSTM) based speech recognition.

The third group of papers included in this volume takes the discussion to fields more closely related to social science. For instance, Crivellari and Beinat [12] demonstrate how neural networks can be employed to address the trajectory prediction problem, especially in context of large-scale mobility traces of short-term foreign tourists. As the authors argue, these trajectories, short and non-repetitive, lack spatial and temporal regularity, which makes predictions based on individual historical motion data unreliable. The approach introduced in their paper promises higher reliability and predictive capacity than those offered by traditional approaches. The value added of these findings rests in their applicability in the decision-making process. Looking at the issue of decision-makers taking advantage of research, Gao et al. [13] examine the relationship between academic research and policy making, especially with regards to research on AI and the emulation of the research findings in the policy-making domain. Zhang et al. [14] make a compelling case for the use of AI-enhanced methods to examine companies' financial performance. As the authors argue, even a fraction of accuracy improvement can result in considerable future savings to a firm and investors. The discussion in the special issue closes with a paper that explores the connection between machine learning and safety and security in modern societies [15]. The authors focus explicitly on the problem of identity spoofing, that is, actions by which a person impersonates a third party to carry out a series of illegal activities such as committing fraud, cyberbullying, sextortion, etc., and ways of mitigating it. In this context, a face recognition system is proposed that, while based on the Histogram of Oriented Gradients (HOG), has the capacity of preventing spoofing.

The inroads of AI and CC in contemporary society create a number of opportunities across issues and domains. This special issue attests to that. At the same time, as AI and AI-enhanced tools proliferate a cognitive gap emerges where substantial parts of societies worldwide remain ignorant as to the nature, thrust and application of AI. A two-fold problem arises: on the one hand, large parts of the societies are suspicious of $\mathrm{AI}$ and AI-enhanced tools, while on the other hand, a great number of citizens is unaware that AI-based solutions are already present in their lives. The same applies to CC and CC-based tools and solutions. The implicit imperative behind this special issue is to encourage a multidisciplinary debate on AI and CC that would allow us to gradually close the gap. The challenge here rests with governments and effective policy responses [16].

Funding: This research received no external funding.

Conflicts of Interest: The authors declare no conflict of interest.

\section{References}

1. Lytras, M.D.; Visvizi, A.; Zhang, X.; Aljohani, N.R. Cognitive computing, Big Data Analytics and data driven industrial marketing. Ind. Mark. Manag. 2020. [CrossRef]

2. Mahmoud, A.A.; Elkatatny, S.; Al Shehri, D. Application of Machine Learning in Evaluation of the Static Young's Modulus for Sandstone Formations. Sustainability 2020, 12, 1880. [CrossRef]

3. Hassan, A.; Elkatatny, S.; Abdulraheem, A. Application of Artificial Intelligence Techniques to Predict the Well Productivity of Fishbone Wells. Sustainability 2019, 11, 6083. [CrossRef]

4. Hassan, A.; Elkatatny, S.; Abdulraheem, A. Intelligent Prediction of Minimum Miscibility Pressure (MMP) During CO2 Flooding Using Artificial Intelligence Techniques. Sustainability 2019, 11, 7020. [CrossRef]

5. Mahmoud, A.A.; Elkatatny, S.; Ali, A.Z.; Abouelresh, M.; Abdulraheem, A. Evaluation of the Total Organic Carbon (TOC) Using Different Artificial Intelligence Techniques. Sustainability 2019, 11, 5643. [CrossRef] 
6. Gowida, A.; Moussa, T.; Elkatatny, S.; Ali, A. A Hybrid Artificial Intelligence Model to Predict the Elastic Behavior of Sandstone Rocks. Sustainability 2019, 11, 5283. [CrossRef]

7. Elkatatny, S. Real-Time Prediction of the Rheological Properties of Water-Based Drill-In Fluid Using Artificial Neural Networks. Sustainability 2019, 11, 5008. [CrossRef]

8. Zhang, H.; Ren, K.; Lin, Y.; Qu, D.; Li, Z. AirInsight: Visual Exploration and Interpretation of Latent Patterns and Anomalies in Air Quality Data. Sustainability 2019, 11, 2944. [CrossRef]

9. Chang, W.; Yuan, X.; Wu, Y.; Zhou, S.; Lei, J.; Xiao, Y. Decision-Making Method based on Mixed Integer Linear Programming and Rough Set: A Case Study of Diesel Engine Quality and Assembly Clearance Data. Sustainability 2019, 11, 620. [CrossRef]

10. Han, T.; Bozorgi, S.M.; Orang, A.V.; Hosseinabadi, A.A.R.; Sangaiah, A.K.; Chen, M.-Y. A Hybrid Unequal Clustering Based on Density with Energy Conservation in Wireless Nodes. Sustainability 2019, 11, 746. [CrossRef]

11. Arslan, R.S.; Barışçı, N. Development of Output Correction Methodology for Long Short Term Memory-Based Speech Recognition. Sustainability 2019, 11, 4250. [CrossRef]

12. Crivellari, A.; Beinat, E. LSTM-Based Deep Learning Model for Predicting Individual Mobility Traces of Short-Term Foreign Tourists. Sustainability 2020, 12, 349. [CrossRef]

13. Gao, J.; Huang, X.; Zhang, L. Comparative Analysis between International Research Hotspots and National-Level Policy Keywords on Artificial Intelligence in China from 2009 to 2018. Sustainability 2019, 11, 6574. [CrossRef]

14. Zhang, Y.; Lee, M. A Hybrid Model for Addressing the Relationship between Financial Performance and Sustainable Development. Sustainability 2019, 11, 2899. [CrossRef]

15. Pujol, F.A.; Pujol, M.J.; Rizo-Maestre, C.; Pujol, M. Entropy-Based Face Recognition and Spoof Detection for Security Applications. Sustainability 2020, 12, 85. [CrossRef]

16. Visvizi, A.; Lytras, M.D. Government at risk: Between distributed risks and threats and effective policy-responses. Transform. Gov. People Process. Policy 2020, 14, 333-336. [CrossRef] 